\title{
A Questionnaire Survey in Kidney Transplant Outpatients: Factors Associated with Good Self-Management
}

\author{
Minako Shimaya1, Mayumi Watanabe ${ }^{{ }^{*},}$ Motoi Azumi1, Kayo Shichiri2, \\ Chikako Tomiyama ${ }^{3}$, Mayumi Tanabe ${ }^{4}$, Sachi Sato ${ }^{4}$, Kouhei Akazawa1 \\ ${ }^{1}$ Department of Medical Informatics, Niigata University Medical and Dental Hospital, Niigata, Japan \\ ${ }^{2}$ Health Administration Center, Niigata University, Niigata, Japan \\ ${ }^{3}$ Department of Medical Technology, Graduate School of Health Sciences, Niigata University, Niigata, Japan \\ ${ }^{4}$ Department of Nursing, Niigata University Medical and Dental Hospital, Niigata, Japan \\ Email: watanabem62@gmail.com
}

Received 16 April 2015; accepted 17 May 2015; published 20 May 2015

Copyright (C) 2015 by authors and Scientific Research Publishing Inc.

This work is licensed under the Creative Commons Attribution International License (CC BY). http://creativecommons.org/licenses/by/4.0/

(c) (7) Open Access

\begin{abstract}
It is very important for outpatients who have had a kidney transplant to take care of themselves after discharge. However, outpatients have limited access to medical care by hospital staff after discharge; therefore, medical staff are unaware of the patient's living conditions, and the uncertainties and problems that they encounter related to self-management. We conducted a questionnaire survey among 161 of 200 outpatients who received kidney transplants to investigate their recognition and actual practice of daily self-management. To determine the characteristics of adherent outpatients, we divided patients into two groups (the adherent and non-adherent group) and compared them. The Chi-squared test was conducted to test the equality of proportions among the groups, and then multiple logistic regression analysis was used to explore the factors significantly associated with regularly taking medicine or failing to take medicine. As a result of the logistic regression model using demographic factors as independent factors, the periods after transplantation ( 2 - 5 and 5 - 10 years) and living-donor kidney transplantation or cadaveric kidney transplantation were selected as significant factors associated with good self-management. As a whole, $68.3 \%$ of the 145 patients were correctly predicted using the model. The results of this study suggest that in the short period after transplantation ( 2 - 5 years), cadaveric kidney transplantation and that the patient has a job are significant factors associated with good self-management. Behind these results, a unique Japanese concept, "amae", could be found. Therefore, medical knowledge and techniques as well as cultural background should be studied.
\end{abstract}

${ }^{*}$ Corresponding author.

How to cite this paper: Shimaya, M., Watanabe, M., Azumi, M., Shichiri, K., Tomiyama, C., Tanabe, M., Sato, S. and Akazawa, K. (2015) A Questionnaire Survey in Kidney Transplant Outpatients: Factors Associated with Good Self-Management. Health, 7, 589-595. http://dx.doi.org/10.4236/health.2015.75070 


\section{Keywords}

\section{Renal Transplantation, Living-Donor Kidney, Cadaveric Kidney, Amae, Multiple Logistic Regression Analysis}

\section{Introduction}

In 1956 our hospital conducted the first cadaveric kidney transplantation in Japan [1] and since then we have conducted $>300$ kidney transplants, including both living-donor kidney transplants and cadaveric kidney transplants. In 2013 in Japan, 1586 kidney transplantations (1431 live kidney and 155 cadaveric kidney transplantations) were performed [2] [3].

It is very important for outpatients who have had kidney transplantations to take care of themselves after discharge. Inpatients have careful nursing by medical staff. However, outpatients have limited access to medical care by nursing staff after discharge. Moreover, they have to check their blood pressure at home daily. Thus, they need to understand the importance of self-management and have the basic knowledge to practice selfmanagement in their daily life. Additionally, outpatients have to take immunosuppressive drugs because these drugs are necessary for graft survival [4]-[6]. However, after discharge, medical staff are unaware of the living conditions of kidney transplant patients, or the uncertainties and problems that they encounter.

Therefore, we conducted a questionnaire survey among 200 outpatients who had had a kidney transplant to investigate their recognition and actual practice of daily self-management. To determine the characteristics of adherent outpatients, we divided patients into two groups, an adherent and a non-adherent group. We studied whether the following factors were associated with good self-management by multivariate analysis: age, gender, period after transplantation (years), experience of dialysis (before transplantation), period of dialysis (years), type of kidney transplantation (living-donor kidney or cadaveric kidney), and whether or not they were employed.

\section{Methods}

\subsection{Participants}

We studied kidney transplant patients at Niigata University Medical and Dental Hospital who received kidney transplants between March 1997 and June 2004. Of 200 patients who left the hospital after kidney transplantation, 39 patients were excluded since they were under age ( $<20$ years old) or they had communication problems. The remaining 161 patients agreed to take part in the study, but 16 cases were omitted for factors such as incomplete forms, a missing signature or excess answers; therefore, 145 patients(male $=91$ and female $=54$ ) were included in the study. Patients were divided into two groups, an adherent $(n=68)$ and a non-adherent group $(n=$ 77). Patients in the former group regularly took medicine, while those in the latter group sometimes forgot to take medicine, even though regularly taking medicine is one of the minimum requirements of self-management. In Short, the former answered "No" while the latter selected "Yes" in Q8 of our questionnaire (Appendix). Details of participants were shown in Figure 1 and Table 1. Written informed consent for participation in the study was obtained from all participants. This study was approved by the Medical Ethics Committee of Niigata University.

\subsection{Demographic Factors}

The demographic factors and the corresponding categories used in this study are shown in Table 1. Patient age (years) was split into five categories: 20 - 29, 30 - 39, 40 - 49, 50 - 59 and $\geq 60$ Q1 (Appendix). Period after transplantation (years) was divided into four categories: <2, 2 - 5, 5 - 10 and $>10$ (Q3). Patients were divided into two categories by the experience of dialysis (before transplantation): "Yes" and "No" (Q4). Those who answered "Yes" were then split into five groups according to the period of dialysis (years): $<1,1$ - 2, 2 - 5, 5 - 10 and $>10$ (Q5). Patients were also divided into two groups by the type of kidney transplant (living-donor kidney transplant or cadaveric kidney transplant) (Q6) and whether they had a job ("Yes" or "No") (Q7). The questionnaire used in this study, which had eight questions, is shown in the Appendix (originally written in Japanese). 


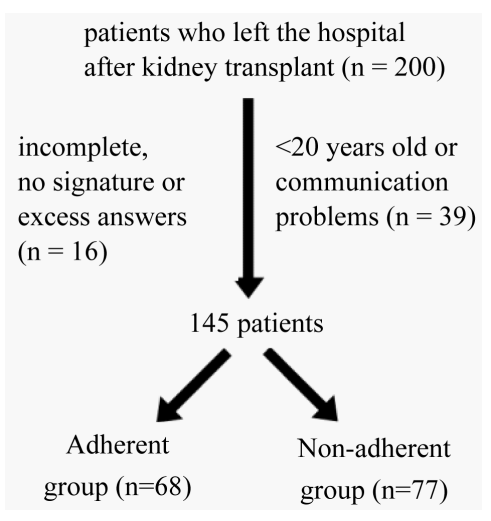

Figure 1. Overview of the 200 patients and two groups: an adherent group (regularly took medicine) and a non-adherent group (sometimes forgot to take medicine, even though regularly taking medicine is one of the minimum requirements of self-management).

Table 1. Characteristics of the adherent and the non-adherent groups $(n=145)$.

\begin{tabular}{|c|c|c|c|c|c|}
\hline \multirow[b]{2}{*}{ Demographic factors } & \multicolumn{2}{|c|}{ Adherent group ( $\mathrm{n}=68$ ) } & \multicolumn{2}{|c|}{ Non-adherent group $(n=77)$} & \multirow{2}{*}{$\mathbf{P}$} \\
\hline & $\mathbf{n}$ & $\%$ & $\mathbf{n}$ & $\%$ & \\
\hline Age (years) & & & & & 0.776 \\
\hline $20-29$ & 7 & 46.7 & 8 & 53.3 & \\
\hline $30-39$ & 12 & 40.0 & 18 & 60.0 & \\
\hline $40-49$ & 14 & 42.4 & 19 & 57.6 & \\
\hline $50-59$ & 19 & 50.0 & 19 & 50.0 & \\
\hline$\geq 60$ & 16 & 44.8 & 13 & 44.8 & \\
\hline Gender & & & & & 0.911 \\
\hline Male & 43 & 47.3 & 48 & 52.7 & \\
\hline Female & 25 & 46.3 & 29 & 53.7 & \\
\hline Period after transplantation (years) & & & & & $<0.001$ \\
\hline$<2$ & 22 & 81.5 & 5 & 18.5 & \\
\hline $2-5$ & 23 & 62.2 & 14 & 37.8 & \\
\hline $5-10$ & 14 & 31.1 & 31 & 68.9 & \\
\hline$>10$ & 9 & 25.0 & 27 & 75.0 & \\
\hline Dialysis (before transplantation) & & & & & 0.702 \\
\hline Yes & 53 & 46.1 & 62 & 53.9 & \\
\hline No & 15 & 50.0 & 15 & 50.0 & \\
\hline Period of dialysis (years) & & & & & 0.097 \\
\hline$<1$ & 28 & 50.0 & 28 & 50.0 & \\
\hline $1-2$ & 5 & 33.3 & 10 & 66.7 & \\
\hline $2-5$ & 5 & 23.8 & 16 & 76.2 & \\
\hline $5-10$ & 7 & 58.3 & 5 & 41.7 & \\
\hline$>10$ & 23 & 56.1 & 18 & 43.9 & \\
\hline Living-donor kidney or cadaveric kidney & & & & & 0.015 \\
\hline Living-donor kidney transplantation & 48 & 41.7 & 67 & 58.3 & \\
\hline Cadaveric kidney transplantation & 20 & 66.7 & 10 & 33.3 & \\
\hline Job & & & & & 0.022 \\
\hline Yes & 28 & 60.9 & 18 & 39.1 & \\
\hline No & 40 & 40.4 & 59 & 59.6 & \\
\hline
\end{tabular}

Pearson's Chi-squared test. Two-tailed significance with $\mathrm{P}$ values $<0.05$. 


\subsection{Statistical Analysis}

The distributions of factors used in this analysis were described in contingency tables. Pearson's Chi-squared test was conducted to test the equality of proportions among groups. Multiple logistic regression analysis was used to explore the factors significantly associated with the adherent group. Candidate factors of the multivariate analysis are shown in Table 1 . Wald tests were performed to test the null hypothesis of no individual factors associated with the not-adherent group in multiple logistic regression analysis. The selection of independent and significant factors was made by a forward stepwise regression method. All statistical tests were two-tailed, and statistical significance was defined as $\mathrm{P}<0.05$. All statistical analyses were performed by using SPSS Statistics for Windows version 20.0 (Armonk, NY, USA: IBM Corp.).

\section{Results}

\subsection{Participant Characteristics}

Table 1 shows the characteristics of the participants of the adherent and non-adherent groups. Participants did not show a significant difference in age or sex (Pearson's Chi-squared test; $\mathrm{P}=0.776$ and 0.911 ). For period after transplantation for the categories <2, 2 - 5, 5 - 10 and $>10$ years, the adherent group indicated $81.5 \%, 62.2 \%$, $31.1 \%$ and $25.0 \%$, respectively; by contrast, the non-adherent group indicated $18.5 \%$, $37.8 \%, 68.9 \%$ and $75.0 \%$, respectively $(\mathrm{P}<0.001)$. In the adherent group, $41.7 \%$ and $66.7 \%$ of patients had had living-donor kidney transplants or cadaveric kidney transplants, respectively. By contrast, in the non-adherent group, $58.3 \%$ and $33.3 \%$ of patients had had living-donor kidney transplants or cadaveric kidney transplants, respectively $(\mathrm{P}=0.015)$.

Moreover, in the adherent group, $60.9 \%$ of patients had a job while $40.4 \%$ did not; by contrast, in the nonadherent group, $39.1 \%$ of patients had a job and 59.6\% did not $(\mathrm{P}=0.022)$. However, neither experience of dialysis (before transplantation) nor period of dialysis differed between the two groups ( $\mathrm{P}=0.702$ and $\mathrm{P}=0.097$ ).

\subsection{Characteristics Associated with Self-Management}

Multiple logistic regression analysis was used to explore the characteristics associated with being able to selfmanage (Table 2). We constructed the logistic regression model using demographic factors as independent factors. As a result, period after transplantation (5 - 10 and $>10$ years) and living-donor kidney transplantation or cadaveric kidney transplantation were selected as significant factors associated with self-management. The odds ratios of period after transplantation of 5 - 10 and $>10$ years were estimated at 10.035 and 12.843 , respectively. The odds ratio of living-donor kidney transplantation or cadaveric kidney transplantation was estimated at 3.082. However, 2 - 5 years for the period after transplantation was not selected as a significant factor associated with self-management. In the model, the adherent and non-adherent groups were correctly predicted $67.6 \%$ and $68.8 \%$, respectively. As a whole, $68.3 \%$ of the 145 patients were correctly predicted (data not shown).

Table 2. Multiple logistic regression model to analyze features of the non-adherent group*

\begin{tabular}{|c|c|c|c|c|c|c|}
\hline \multirow{2}{*}{ Variables } & \multirow{2}{*}{ Coefficients } & \multirow{2}{*}{ Std. error } & \multirow{2}{*}{$\mathbf{P}$} & \multirow{2}{*}{ Odds ratio } & \multicolumn{2}{|c|}{$95 \% \mathrm{CI}$} \\
\hline & & & & & Lower & Upper \\
\hline \multicolumn{7}{|c|}{ Period after transplantation (years) } \\
\hline$<2^{* *}$ & - & - & - & 1 & & \\
\hline $2-5$ & 0.886 & 0.609 & 0.146 & 2.425 & 0.739 & 8.005 \\
\hline $5-10$ & 2.306 & 0.604 & $<0.001$ & 10.035 & 3.072 & 32.784 \\
\hline$>10$ & 2.553 & 0.639 & $<0.001$ & 12.843 & 3.672 & 44.924 \\
\hline \multicolumn{7}{|c|}{ Live kidney or cadaveric kidney } \\
\hline Cadaveric kidney & - & - & - & 1 & & \\
\hline Living-donor kidney & 1.125 & 0.482 & 0.020 & 3.082 & 1.128 & 7.579 \\
\hline Constant & -2.353 & 0.645 & 0.580 & 1.356 & & \\
\hline
\end{tabular}

*Factors significantly associated with the non-adherent group were selected by a forward stepwise regression method; ${ }^{* *}$ Reference group. 


\section{Discussion}

\subsection{The Period after Transplantation (2 - 5 Years) and Cadaveric Kidney Transplantation}

In this study, features of adherent kidney transplant outpatients were studied though analysis of questionnaire responses. Table 1 shows that $81.5 \%$ and $62.2 \%$ of patients who received a kidney transplant within 5 years $(<2$ and 2 - 5 year groups, respectively) regularly took medicine. However, only $31.1 \%$ and $25.0 \%$ of patients who received a kidney transplantation more than 5 years ago ( 5 - 10 and >10 year groups, respectively) regularly took medicine. The findings above were also supported by the results of the logistic regression analysis. "We may say that vows made in storms are forgotten in claims". In short, the passage of time might weaken patients' initial resolve to self-manage. In this way, even an "adherent" patient may become a "non-adherent" patient as time goes by. Medical staff may help patients to retain their resolve to self-manage when they meet at routine examinations.

The most interesting result was the different proportion of patients with a living-donor kidney transplantation or a cadaveric kidney transplantation in the adherent and non-adherent groups. This result was also supported by the logistic regression analysis because living-donor kidney or cadaveric kidney was selected as a significant factor associated with drug compliance. In short, it is possible that patients who had a cadaveric kidney transplantation managed themselves better than those who had a living-donor kidney transplantation. To the best of our knowledge, this study is the first to report this interesting and unexpected result.

Living-donor kidneys are usually donated from a blood relative, while cadaveric kidneys are donated by a stranger. Therefore, cadaveric kidney donation cannot meet the needs of all patients who require a kidney transplantation in Japan. In the USA, the waiting time for a deceased kidney donation may be 2 - 5 years [7]. In Japan, 12,757 patients are on the waiting list for kidney transplantation and only 155 of them had a kidney transplantation operation in 2013. Moreover, young patients ( $<16$ years old) have priority over older patients ( $\geq 16$ years old). In consequence, the average waiting time for kidney transplantation is 4695 days (12.9 years) in Japan; for young patients the figure is 1401 (3.8 years), while for patients $\geq 16$ years old the figure is 5087 (13.9 years) [8]. Subjects in this study were 20 years of age and older. The patients in this study who received cadaveric kidneys might highly appreciate the rare chance to have this type of transplantation and, therefore, could have better selfmanagement than those who received living-donor kidneys.

In Japan, living-donor kidneys are donated from family members (such as brothers, sisters, parents and children). Although fatality resulting from live kidney donation is extremely rare, the risks of donation are considered similar to those involved with any major surgery, such as bleeding and infection. Donors face physical and mental burdens.

\subsection{A Japanese Unique Concept, "Amae"}

We also studied the cultural background of the patients (all subjects were Japanese). Doi advocated a unique Japanese concept, which is called "amae". It is understood as a unique and comfortable relationship of dependency among Japanese [9] [10], and such a concept of "amae" is pervasive in Japanese life [11]. Patients who do not receive cadaveric kidneys, would expect living-donor kidneys from relatives. In Japan, donors of livingdonor kidneys are limited to relatives. Therefore, it is not difficult to understand the patient's degree of dependency to their healthy relative. Moreover, "amae" has a resemblance to the ideal relationship of the parent-child, and all other relationships may strive for this degree of closeness [9] [10]. In an extreme case medical staff sometimes comes across an alarming abuse, "A strict diet and lifestyle guidance shall kill me" or "I could die if I cannot drink". Thus, the unique concept of "amae" exists in the context of the Japanese cultural background, and we might find other factors to explain the difference of adherent patients and non-adherent patients.

In the Chi-square test, the factor "with or without a job" showed a P value of 0.022; however, this finding was not supported by the results of the logistic regression analysis. Patients with jobs lead regular lives and they can routinely take medicine. By contrast, it is not as easy for a patient without a job because their daily routine is not controlled by their work. Therefore, they may forget to take medicine.

The results of this study are important for medical staff in order to improve the quality of medical intervention as well as the quality of life of patients. However, our study has several limitations. First, the number of cases were limited in this study, therefore, further research, such as larger scale studies, are required to support the findings. Second, "amae" is a unique Japanese concept and patients with different cultural backgrounds should 
be studied for comparison. Third, we did not investigate personality tendencies of each patient, for example, if their attitudes were optimistic or pessimistic. Moreover, we did not inquire about their family relationships, educational background and income. These would be valuable factors to assess in any future study.

\section{Conclusion}

The results of this study suggest that the short periods after transplantation (2 - 5 years) and cadaveric kidney transplantation are factors significantly associated with self-management. Additionally, whether patients have a job or not is another significant factor. Behind these results, a Japanese unique concept, "amae”, could also be found. We consider that the cultural background of patients as well as the knowledge and techniques of medical staff must be studied.

\section{Acknowledgements}

The authors wish to thank all medical staff, especially nursing staff, and patients who participated in this study.

\section{References}

[1] Inoue, H., Takayanagi, T., Suzuki, A., Sato, S., Hirokawa, I., Kawaji, K. and Ikoma, F. (1956) Experience with Renal Homotransplantation in the Human: A Case of Mercury Bichloride Intoxication. The Japanese Journal of Urology, 47, 857-886.

[2] The Japan Society for Transplantation, Japanese Society for Clinical Renal Transplantation (2014) Annual Progress Report from the Japanese Renal Transplant Registry: Number of Renal Transplantation in 2013 and Follow-Up Survey. The Japan Society for Transplantation, 49, 240-260.

[3] The Japan Society for Transplantation. http://www.asas.or.jp/jst/pro/pro8.html

[4] Kadowaki, M., Saito, M., Amada, N., Haga, I., Nakamura, A. and Tokodai, K. (2014) Medication Compliance in Renal Transplant Patients during the Great East Japan Earthquake. Transplantation Proceedings, 46, 610-612. http://dx.doi.org/10.1016/j.transproceed.2013.11.039

[5] Nevins, T.E., Kruse, L., Skeans, M.A. and Thomas, W. (2001) The Natural History of Azathioprine Compliance after Renal Transplantation. Kidney International, 60, 1565-1570. http://dx.doi.org/10.1046/j.1523-1755.2001.00961.x

[6] Morrissey, P.E., Reinert, S., Yango, A., Gautam, A., Monaco, A. and Gohh, R. (2005) Factors Contributing to Acute Rejection in Renal Transplantation: The Role of Noncompliance. Transplantation Proceedings, 37, 2044-2047. http://dx.doi.org/10.1016/j.transproceed.2005.03.017

[7] University of Maryland Medical Center (2015) Living Donor Kidney Transplant Program. http://umm.edu/programs/transplant/services/kidney/living-donor\#ixzz3T2Rb02dp

[8] Japan Organ Transplant Network Homepage (2015) http://www.jotnw.or.jp/datafile/

[9] Doi, T. (1981) The Anatomy of Dependence: The Key Analysis of Japanese Behavior. 2nd Edition, Kodansha International, Tokyo.

[10] Johnson, F.A. (1992) Dependency and Japanese Socialization: Psychoanalytic and Anthropological Investigations in Amae. New York University Press, New York.

[11] Gibney, F. (1975) Japan: The Fragile Superpower. Norton. 


\section{Appendix}

Kindly take a few minutes and choose only one best answer to complete the following questionnaire and then hand it back to us.

Q1. Please choose your age group. (Age)
$\square 0: 20$ - 29 years old
$\square 1: 30$ - 39 years old
$\square 2: 40$ - 49 years old
$\square 3: 50$ - 59 years old
$\square 4: \geq 60$ years old

Q2. You are male or female? (Gender)

\section{$\square 0$ : Male}

$\square$ 1: Female

Q3. Please choose the period after transplantation. (Years) (Period after transplantation)
$\square 0$ : $<2$ years
$\square 1: 2$ - 5 years
$\square 2: 5$ - 10 years
$\square 3$ : $>10$ years

Q4. Before kidney transplantation, did you receive dialysis? (Dialysis before transplantation)

$\square 0$ : No (If No, please skip the next question)

$\square$ : Yes (If Yes, please answer the next question)

Q5. Please choose one group for the period of dialysis before the kidney transplantation. (Period of dialysis)

$\square 0$ : $<1$ year

$\square 1: 1$ - 2 years

$\square 2: 2$ - 5 years

$\square 3: 5$ - 10 years

$\square 4:>10$ years

Q6. Did you have a living-donor kidney transplantation or a cadaveric kidney transplant? (Living-donor kidney or Cadaveric kidney)

$\square 0$ : Living-donor kidney transplantation

$\square$ 1: Cadaveric kidney transplantation

Q7. Do you have a job? (Job)
$\square 0$ : No

$\square$ 1: Yes

Q8. Have you forgotten to take medicine prescribed at the hospital? $(0=$ Adherent; $1=$ Non-adherent $)$

$\square 0$ : No

$\square$ 1: Yes

Thank you very much. 